\title{
Verification of the LWRARC Code for Light-Water-Reactor Afterheat Rate Calculations
}

Manuscript Completed: March 1997

Date Published: February 1998

Prepared by

B.D. Murphy

Oak Ridge National Laboratory

Managed by Lockheed Martin Energy Research Corp.

Oak Ridge, TN 37831-6370

C.W. Nilsen, NRC Project Manager

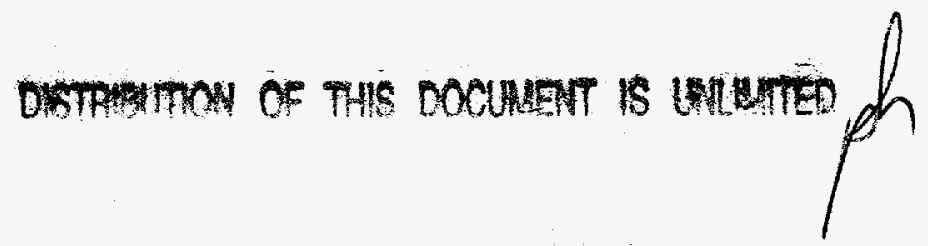

Prepared for

Division of Regulatory Applications Office of Nuclear Regulatory Research U.S. Nuclear Regulatory Commission Washington, DC 20555-0001 NRC Job Code W6651

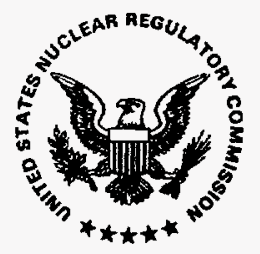




\section{DISCLAIMER}

This report was prepared as an account of work sponsored by an agency of the United States Government. Neither the United States Government nor any agency thereof, nor any of their employees, makes any warranty, express or implied, or assumes any legal liability or responsibility for the accuracy, completeness, or usefulness of any information, apparatus, product, or process disclosed, or represents that its use would not infringe privately owned rights. Reference herein to any specific commercial product, process, or service by trade name, trademark, manufacturer, or otherwise does not necessarily constitute or imply its endorsement, recommendation, or favoring by the United States Government or any agency thereof. The views and opinions of authors expressed herein do not necessarily state or reflect those of the United States Government or any agency thereof. 


\section{DISCLAIMER}

Portions of this document may be illegible electronic image products. Images are produced from the best available original document. 


\begin{abstract}
This report describes verification studies carried out on the LWRARC (Light-Water-Reactor Afterheat Rate Calculations) computer code (see ref. 1, Sect. 7). The LWRARC code is proposed for automating the implementation of procedures specified in Draft Revision 1 of the U.S. Nuclear Regulatory Commission (NRC) Regulatory Guide 3.54, "Spent-Fuel Heat Generation in an Independent Spent-Fuel Storage Installation," which gives guidelines on the calculation of decay heat for spent nuclear fuel.

Draft Regulatory Guide 3.54 allows one to estimate decay-heat values by means of a table lookup procedure with interpolation performed between table-entry values. The tabulated values of the relevant parameters span ranges that are appropriate for spent fuel from a boiling-water reactor (BWR) or a pressurized-water reactor (PWR), as the case may be, and decay-heat rates are obtained for spent fuel whose properties are within those parameter limits. In some instances, where these limits are either exceeded or where they approach critical regions, adjustments are invoked following table lookup.

The LWRARC computer code is intended to replicate the manual process just described. In the code, the table lookup is done by entering a database and carrying out interpolations. The code then determines if adjustments apply, and, if this is the case, adjustment factors are calculated separately. The manual procedures in the Draft Regulatory Guide have been validated (i.e., they produce results that are good estimates of reality). The work reported in this document verifies that the LWRARC code replicates the manual procedures of the Draft Regulatory Guide, and that the code, taken together with the Draft Regulatory Guide, can support both verification and validation processes.
\end{abstract}





\section{CONTENTS}

Page

ABSTRACT iii

LIST OF FIGURES

vi

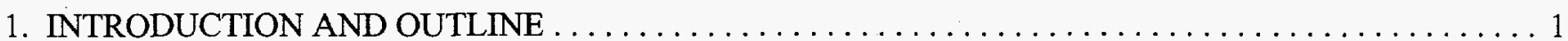

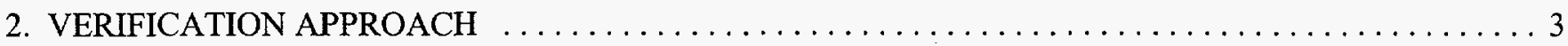

3. DETAILS OF THE VERIFICATION PROCESS $\ldots \ldots \ldots \ldots \ldots \ldots \ldots \ldots \ldots \ldots \ldots \ldots \ldots \ldots \ldots$

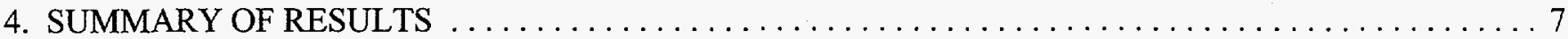

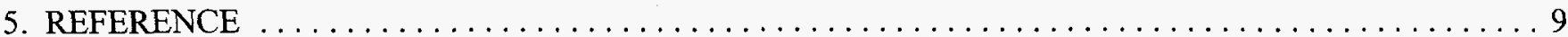




\section{LIST OF FIGURES}

\section{Figure}

Page

1 Test points used for BWR cases

6

2 Test points used for PWR cases

6

3

The distribution of cooling times

6 


\section{INTRODUCTION AND OUTLINE}

The process to be described in this report is for the purpose of ensuring that the LWRARC (Light-WaterReactor Afterheat Rate Calculations) code does indeed reproduce the results from Draft Regulatory Guide 3.54. The results obtained using the procedures in Draft Revision 1 of Regulatory Guide 3.54 were compared with LWRARC computations. Table lookup/interpolation was checked for validity, and, in turn, the need for any adjustment factors was investigated. If called for, adjustment factors were calculated and verified.

The verification efforts involve two sets of independent calculations: calculations using the LWRARC code and calculations using the procedures outlined in the Draft Regulatory Guide. The calculations performed using the Regulatory Guide are referred to as manual calculations. For efficiency purposes, the manual calculations were sometimes performed with the help of a spreadsheet. (The verification calculations involve the Draft Regulatory Guide. They will, of course, be applicable also to the Regulatory Guide itself when it evolves beyond the draft stage.)

The parameters to be specified in estimating decay-heat generation rates are the following:

(1) whether the spent fuel is from a boiling-water reactor (BWR) or a pressurized-water reactor (PWR),

(2) the average specific power over the reactor's operating history (in $\mathrm{kW} / \mathrm{kgU}$ ),

(3) the fuel burnup (in $\mathrm{MWd} / \mathrm{kgU}$ ), and

(4) the cooling time (years).

With these four parameters, one determines the decay-heat generation rates (e.g., in watts $/ \mathrm{kgU}$ ) for a certain type of light-water-reactor (LWR) fuel with a given burnup history at some time following discharge. Having determined a decay-heat value via tabular interpolation, one can then calculate adjustment factors that may apply. There are three areas where an adjustment factor may be applied following table lookup. Finally, an overall percentage safety factor is applied.
The adjustment factors apply to the following situations:

(1) The short-cooling-time situation. If the specific power toward the end of the reactor's operating history is significantly different from its average value, an adjustment factor will be needed in cases where the cooling time is seven years or less. The specific power levels for both the final and penultimate cycles are checked, and each one can contribute an adjustment factor.

(2) The excess-power situation. The Draft Regulatory Guide assumes a maximum power level for each type of reactor $(30 \mathrm{~kW} / \mathrm{kgU}$ for a BWR and $40 \mathrm{~kW} / \mathrm{kgU}$ for a PWR), and the interpolation tables reflect this. If the power level exceeds the maximum, an adjustment factor must be applied. However, if the power level is more than $35 \%$ in excess of the maximum, the procedures in the Draft Regulatory Guide are not recommended.

(3) The enrichment situation. In making decayheat estimates it is assumed that a given amount of burnup (energy extracted per mass of heavy metal) is dependent on the enrichment or, in other words, the amount of fissile material. As a result, burnup and enrichment are correlated. When the actual enrichment deviates from the value expected by virtue of the burnup, an enrichment adjustment factor is applied.

Finally, an overall percentage safety factor is calculated. This safety factor varies with burnup and cooling time and is slightly different in magnitude (although qualitatively similar) in the case of a BWR and a PWR.

The foregoing contains a brief summary of the estimation of decay heat as outlined in the Draft Regulatory Guide. For a detailed description of how these calculations are performed, one should consult the report by Hermann, Parks, and Renier. ${ }^{1}$ 



\section{VERIFICATION APPROACH}

For verification, cases were chosen from within the range of applicability of the approach and for those cases the results of manual calculations were compared with LWRARC results. Parameters used for tabular interpolation are specific power, burnup, and cooling time, and values of these were chosen so as to be statistically representative within the applicable range (i.e., they were randomly chosen from within, and are representative of, the appropriate parameter range).

For verification from within the tables (i.e., requiring no adjustment factors), $18 \mathrm{BWR}$ and 18 PWR cases were chosen, all within the ranges of the three basic parameters (specific power, burnup, and cooling time).

A second level in the verification process involved cases needing adjustment factors. Again, the parameters were chosen randomly from within the range of applicability. In the case of the short cooling time and excess-power adjustment factors, the relevant parameters were representative of a more restrictive range (i.e., cooling times were less than seven years and power levels were between 1.00 and 1.35 times the table maxima).

Eighteen BWR and 18 PWR cases were chosen where an enrichment adjustment factor was needed. In each case, the enrichment adjustment factor was checked, and the decay-heat value without the adjustment factor was also checked.

For the situation where the cooling time is less than seven years, nine BWR cases and nine PWR cases were chosen for study. For each one of these 18 cases, two adjustment factors were calculated, one for each of the last two reactor cycles. The decay-heat value before the application of either adjustment factor (the table lookup value) was also checked for each case.

Eighteen BWR and 18 PWR cases were selected to test the excess-power adjustment factor. 



\section{DETAILS OF THE VERIFICATION PROCESS}

Verification checks that have been performed are as follows:

- Random choices for parameters within recommended ranges and requiring no adjustment factors: Eighteen cases have been analyzed for BWR fuel, and 18 cases have been analyzed for PWR fuel.

- Random choices of parameters within recommended ranges but where the enrichment was perturbed from its optimum value: Eighteen cases have been run for BWR fuel and 18 cases for PWR fuel. In all 36 of these cases the tabular predictions from LWRARC have been checked, as have the adjustment factors.

- Random choices where the cooling time was confined to seven years or less: Nine BWR cases were studied, as were nine PWR cases. For each case, a short-cooling-time correction was required for the last and next-to-last reactor cycle (i.e., one of each type of correction factor for each BWR and each PWR case). Furthermore, the predicted tabular values were checked for each of these 18 cases.

- Excess-power adjustment factor tests were performed on 18 cases involving BWR fuel and 18 cases involving PWR fuel. These cases were not required to be checked for tabular interpolation because they require the power to be out of range. For three of the cases, the power was chosen to be just short of the end of the valid range, and this confirmed that the adjustment factor was being implemented in LWRARC as intended.

Following tabular interpolation and determination of adjustment factors, LWRARC calculates a final safety factor. This safety factor has been calculated and verified for the 126 independent cases studied.

Thus this verification effort has involved the following:

a. 36 cases from within the tables and requiring no adjustment factors; b. 36 cases requiring an enrichment adjustment factor;

c. 18 independent cases with short cooling times (two adjustment factors per case); and

d. 36 cases requiring an excess-power adjustment factor.

Figures 1 and 2 indicate how the test cases fall with respect to specific power and burnup. For a $\mathrm{BWR}$, the specific-power range is $12-30 \mathrm{~kW} / \mathrm{kgU}$, and the burnup range is $20-45 \mathrm{MWd} / \mathrm{kgU}$. For a PWR, the corresponding values are $18-40 \mathrm{~kW} / \mathrm{kgU}$ and 25-50 MWd $/ \mathrm{kgU}$. Both figures show the values for specific power and burnup and refer respectively to the cases chosen for BWR and PWR fuel. It is clear that the chosen test points fall randomly within the parameter space. We show these two parameters (average power and burnup) so that one can see that there is no correlation between the values chosen. We show data on the choices of cooling times separately. We could have shown the data in other combinations; however, it was considered important to be assured that there were no correlations between the choices of average power and burnup. Figures 1 and 2 show cases from $a, b$, and $c$ of the preceding list.

Figure 3 gives a synopsis of the choices of cooling times. Cooling times out to 110 years are examined by the Draft Regulatory Guide, and Fig. 3 shows the number of cases in each of eleven 10-year intervals. Again, it seems clear that the range of cooling times is covered in a manner that is representative and random. Figure 3, of course, does not contain the cases where the short-cooling-time adjustment factors were tested (i.e., where cooling times were specifically chosen to be less than seven years). Thus Fig. 3 shows cases from $a, b$, and $d$ of the preceding list.

To simplify the verification process, the test cases were all run assuming four reactor cycles. Of course the results should be independent of the number of cycles. (However, in the short-cooling-time case one would like to check the last two cycles, and it is therefore desirable to have more than two cycles in that instance.) A check was made to see that the number of reactor cycles was not affecting the results. From among the cases already tested, four BWR and 


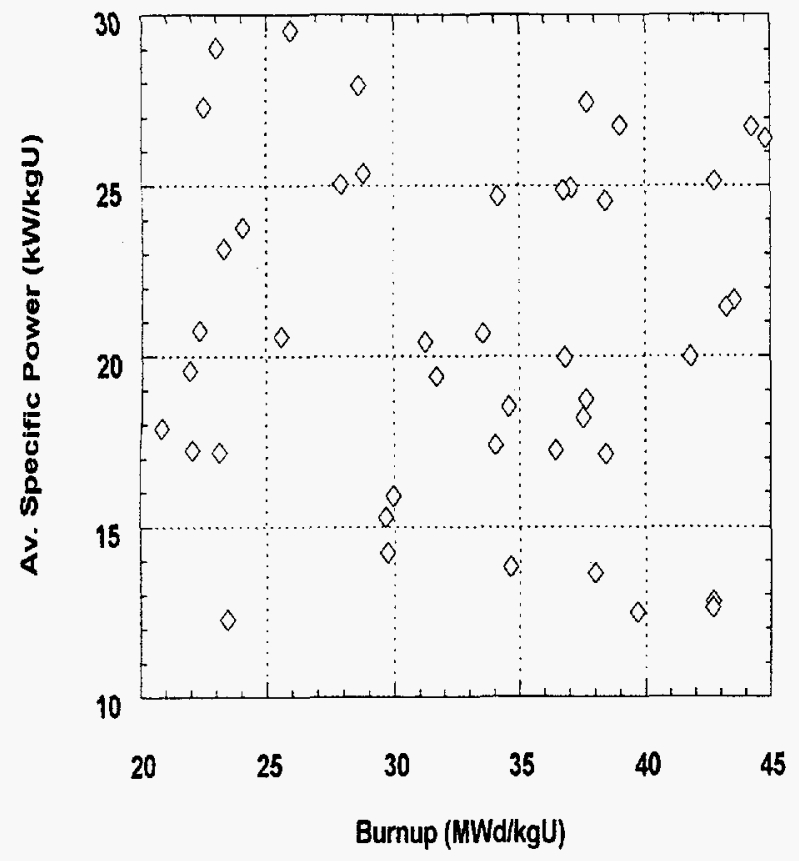

Figure 1 Test points used for BWR cases (pertinent ranges are $20-45 \mathrm{MWd} / \mathrm{kgU}$ and $12-30 \mathrm{~kW} / \mathrm{kgU}$ )

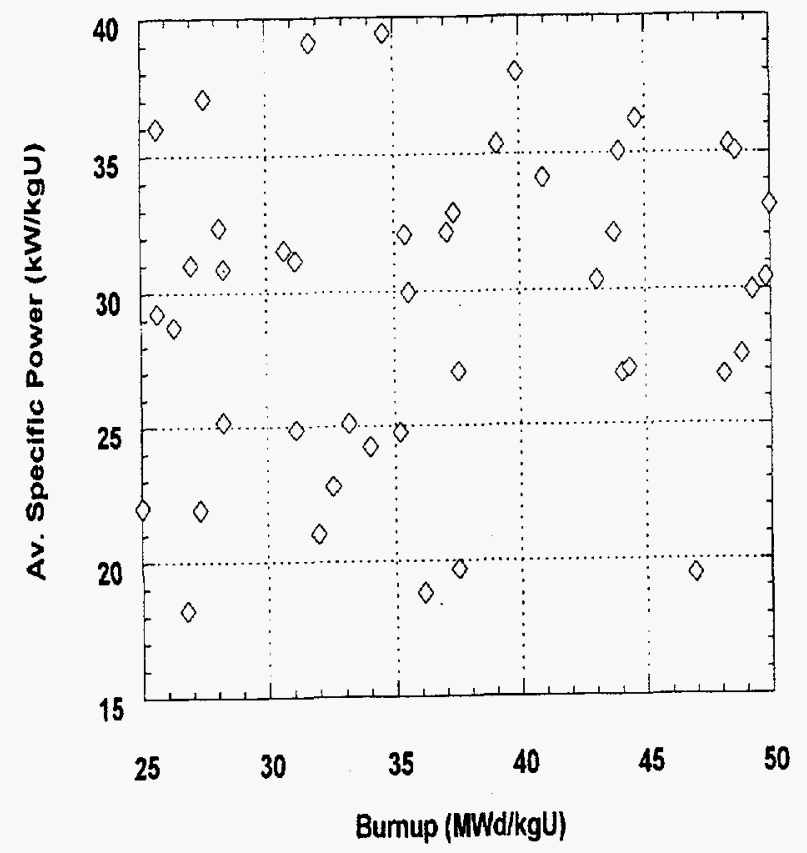

Figure 2 Test points used for PWR cases (pertinent ranges are $25-50 \mathrm{MWd} / \mathrm{kgU}$ and $18-40 \mathrm{~kW} / \mathrm{kgU}$ )

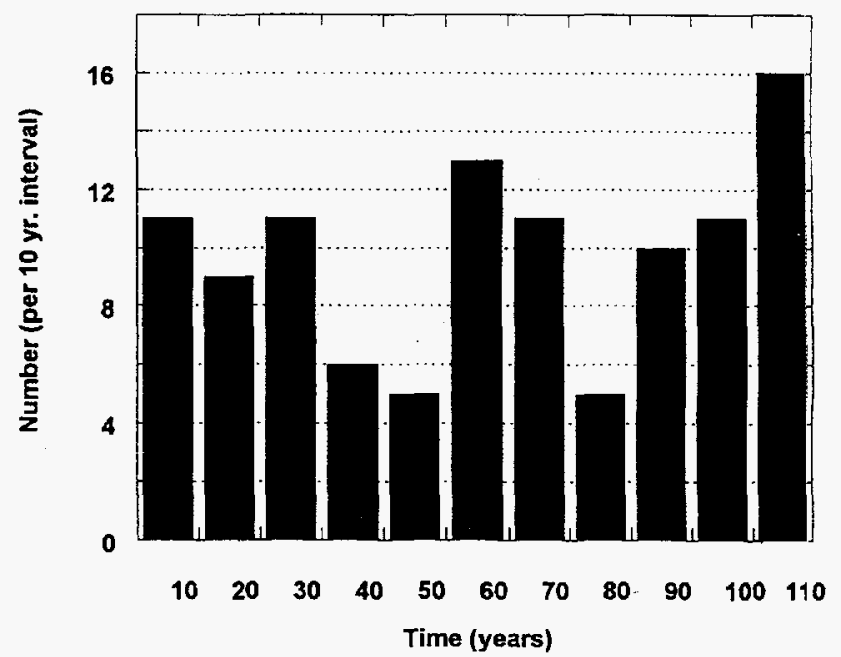

Figure 3 The distribution of cooling times

four PWR cases were randomly selected. All of these cases had been tested for four cycles. For the four cases (BWR and PWR) in order, the previous calculations were repeated using one, two, three, and ten cycles, respectively. All results were in agreement with those obtained using four cycles. 


\section{SUMMARY OF RESULTS}

For the cases that are detailed in Sect. 3, both the manual Draft Regulatory Guide results and the automated LWRARC calculations have been compared. All values were calculated to three decimal places. Taking into account the range of values of the calculated parameters, this translates to a precision that is in the range of $1 \%$ to somewhere below $0.1 \%$. When differences were seen between manual calculations and LWRARC values, those differences occurred in the last decimal place. In all cases except one, the difference was one number in the last decimal digit. The one exception was a difference of two in the last decimal digit. This could mean that many of the differences are simply the result of roundoff effects. The variance rates are shown quantitatively in the table below. These variances are small. There is no significant difference between the values calculated using the LWRARC code and those calculated manually according to the procedures outlined in Draft Regulatory Guide 3.54.

Care has been exercised to ensure that all choices of all parameters have been representative of the areas of parameter space being investigated. Furthermore, to be representative of the parameter ranges being checked, and to ensure unbiased choices, all values were chosen randomly within the ranges being investigated. A random-number generator was used for this purpose.

Summary of calculational variances

Percentage of cases

with variance
Largest variance (\%)
Tabular interpolation values

Adjustment-factor calculations

Safety-factor calculations
11

16

\section{3}

0.1

No variances (all in agreement to three decimal places) 



\section{REFERENCE}

1. O. W. Hermann, C. V. Parks, and J. P. Renier, Technical Support for a Proposed Decay Heat Guide Using SAS2H/ORIGEN-S Data, NUREG/CR-5625 (ORNL-6698), U.S. Nuclear Regulatory Commission, September 1994. 